\title{
Impactos ambientais do turismo: um estudo sobre a percepção de moradores e turistas no Município de Paraty-RJ
}

\author{
Environmental impacts of tourism: a study on the perceptions of residents and tourists in the Municipality of Paraty-RJ
}

\author{
Morto Baiém Fandé', Vania Filippi Goulart Carvalho Pereira' \\ ' Universidade Severino Sombra, Vassouras, Brasil.
}

\section{Resumo}

O elevado crescimento do turismo, desde década de 50, foi acompanhado de diversos impactos ambientais nas destinações turísticas. Estes impactos, que muitas vezes não são percebidos ou são ignoradas por motivos financeiros, podem produzir, entre outros efeitos, o declínio do fluxo turístico. As zonas litorâneas, umas das destinações mais procuradas por turistas, devido às atrações naturais que apresentam, são vulneráveis a qualquer tipo de pressão antrópica. Este estudo avaliou, comparativamente, a percepção por parte de moradores e de turistas sobre os impactos ambientais causados pela atividade turística no Município de Paraty-RJ. Para o efeito, foi aplicado, aleatoriamente, um questionário aos moradores e turistas neste município, analisando ambiente natural, ambiente transformado e ambiente sociocultural. Os resultados obtidos da pesquisa indicaram que tanto moradores quanto turistas perceberam, ainda que em graus diferentes, danos ao ambiente, provocados pela atividade turística na localidade receptora. Os próprios moradores, que se mostraram mais pessimistas na avaliação de impactos ambientais negativos, têm consciência sobre o seu papel com o meio ambiente. Ficou evidente a necessidade de melhorias no planejamento turístico, adoção de medidas políticas e ações coordenadas, entre os setores público e privado, que priorizem a aspecto ambiental visando à conservação do meio ambiente e o turismo sustentável.

Palavras-chave: Ação antrópica, Região costeira, Turismo.

\begin{abstract}
The high growth of tourism since the 1950's has been accompanied by various environmental impacts on tourist destinations. These impacts, which are often unnoticed or ignored for financial reasons can produce, among other effects, the decline of tourist flow. Coastal zones, one of the most sought after destinations for tourists due to the natural attractions thereof, are vulnerable to any kind of anthropogenic pressure. This study comparatively evaluated the perception by locals and tourists on environmental impacts caused by tourism in the Municipality of Paraty - RJ. For that purpose, a questionnaire was applied randomly to residents and tourists in this municipality analyzing natural environment, transformed environment and sociocultural environment. The results of the survey indicated that both locals and tourists realized, albeit in different degrees, damage to the environment caused by tourist activity in the receiving location. The residents themselves, who were more pessimistic in assessing the negative environmental impacts, are aware of their role in the environment. It became evident that there is need for improvements in tourism planning, adoption of measures, policies and coordinated actions between the public and private sectors that prioritize the environmental aspect, aiming at the conservation of the environment and sustainable tourism.
\end{abstract}

Keywords: Human action. Coastal region. Tourism. 


\section{INTRODUÇÃO}

O turismo moderno, caracterizado por fenômeno de massa, causa diversos efeitos nas comunidades e nos centros receptores. Tradicionalmente, os pesquisadores têm concentrado os seus estudos sobre a influência econômica do turismo e da recreação nas destinações turísticas. Estes tendem a considerar a geração de divisas, a importância e as características do gasto feito pelos turistas, a geração de emprego e o papel do turismo como agente de desenvolvimento regional. Contudo, é evidente que a atividade turística gera outros efeitos, principalmente ambientais, sociais e culturais (CASASOLA, 2003).

O crescimento acelerado do turismo, a partir da década de 50, provocou uma degradação de recursos turísticos em todo o planeta (RUSCHMANN, 2008). A mesma autora afirma que só a partir da década de 70 a qualidade do meio ambiente começou a ganhar destaque como elemento do produto da atividade turística.

Dias (2005, p. 100) corrobora o trabalho da autora acima, fazendo o seguinte comentário:

Os estudos dos efeitos do turismo no meio ambiente começaram a ser intensificados na segunda metade da década de 70, em função do crescimento do turismo de massas e de vários problemas causados pela atividade turística, que fizeram soar um alerta mundial, apontando para a possibilidade de que seu crescimento poderia ser insustentável do ponto de vista ambiental.

Em seu trabalho, Bartholo Junior et al. (2005, p. 18) também fizeram o seguinte comentário:

"O rótulo da 'indústria limpa' é demonstrado como falacioso: o turismo gera impactos no meio natural em que estiver alocado, na cultura de comunidades e povos".

O exercício da atividade turística provoca impactos ambientais positivos e negativos, envolvendo o ambiente natural, o ambiente transformado e o ambiente sociocultural. No entanto, o ambiente natural é mais vulnerável aos impactos ambientais negativos do turismo.

Os impactos positivos do turismo decorrem do fato de esta atividade poder subsidiar os custos de conservação do ambiente (BELTRÃO, 2001). Outros impactos positivos do turismo são a conservação da herança cultural, o fortalecimento da identidade cultural e o intercâmbio intercultural (DIAS, 2005).

Os principais impactos ambientais negativos do turismo são: poluição e contaminação de cursos de água e de praias; poluição atmosférica, visual e sonora; desmatamento, distúrbios à vida selvagem e perda de biodiversidade; congestionamento; compactação, erosão e perda de fertilidade do solo; danos a monumentos, sítios arqueológicos, lugares e construções históricas; choques culturais; transformação dos valores e condutas morais; difusão de epidemias; sexo, crime e mercantilização da cultura (FERRETTI, 2002; DIAS, 2005).

De acordo com Dias (2005, p. 100):

"[...] uma lista dos impactos ambientais provocados pelo turismo será sempre incompleta pela diversidade de efeitos que a atividade provoca no meio ambiente, daí a necessidade de monitoramento permanente".

Os efeitos negativos do turismo podem ser evitados ou atenuados através de planejamento turístico integrado, que considera aspectos tradicionais do planejamento (mercado, econômicos, financeiros, técnicos e coordenação do território) e planejamento ecológico, que inclui aspectos ambientais (CASASOLA, 2003). O planejamento sustentável do turismo pode gerar conflitos durante seu desenvolvimento, mas a compensação virá no futuro, com rentabilidade a longo prazo (VALLS, 2006).

O presente trabalho teve por objetivo principal identificar e comparar a percepção, por parte de moradores e turistas, dos impactos ambientais causados pela atividade turística no Município de Paraty-RJ, Brasil. A abordagem abrangeu as três dimensões do ambiente: ambiente natural, ambiente construído e ambiente sociocultural. O Município de Paraty é uma das mais importantes destinações turísticas da Região Turística Costa Verde, Estado do Rio de Janeiro, e cerca de 80 \% do seu território (PARATY, 2003) é ocupado por Unidades de Conservação: Área de Proteção Ambiental de Cairuçu, Estação Ecológica de Tamoios, Parque Nacional da Serra da Bocaina, Reserva Ecológica da Juatinga, Parque Municipal do Morro do Forte e Área Estadual de Lazer de Paraty-Mirim. 


\section{METODOLOGIA}

Neste trabalho foi realizada uma pesquisa exploratória e de campo em várias comunidades do Município de Paraty, entre 03 de Janeiro a 03 de Agosto de 2013. Foram aplicados 33 questionários fechados, com nove perguntas, aos moradores do município e a turistas, maiores de idade (entende-se maior de idade pessoa com idade igual ou maior que 18 anos), abordados aleatoriamente, em diferentes dias. A abordagem foi feita em praias, residências, estabelecimentos públicos e privados, entre outros locais.

Aos entrevistados foi solicitado que indicassem a significância de distúrbios e danos causados aos ecossistemas marinhos por algumas atividades ou atos ligados, direta ou indiretamente, ao turismo, onde I corresponde aos "distúrbios e danos não significativos", II aos "distúrbios e danos pouco significativos", III aos "distúrbios e danos moderadamente significativos", IV aos "distúrbios e danos significativos" e V aos "distúrbios e danos muito significativos".

\section{RESULTADOS E DISCUSSÃO}

Conforme dados apurados da pesquisa, a maioria dos entrevistados avaliou como causadores de "distúrbios e danos muito significativos" aos ecossistemas marinhos, respectivamente, a disposição de resíduos sólidos em praias (58,3\% de moradores e $81 \%$ de turistas), os produtos químicos de barcos $(66,7 \%$ de moradores e de turistas), o efluente doméstico $(66,7 \%$ de moradores e $61,9 \%$ de turistas) e a erosão e deposição ( $75 \%$ de moradores e 33,3 \% de moradores). O mesmo nível de distúrbios e danos foi indicado por uma percentagem relativamente baixa dos entrevistados, quando avaliaram a pesca profissional ( $8,3 \%$ de moradores e $4,8 \%$ de turistas), a pesca por esporte $(8,3 \%$ de moradores e $14,8 \%$ de turistas), o artesanato ( $25 \%$ de moradores e $0 \%$ de turistas), o ruído de barcos recreativos ( $25 \%$ de moradores e 4,8 de turistas) e o mergulho ( $41,7 \%$ de moradores e $9,5 \%$ de turistas). $\mathrm{O}$ quadro 1 apresenta a distribuição dos resultados pelos cinco níveis de significância considerados na visão de moradores e de turistas.

Quadro 1 - Resultados, em porcentagem, na visão dos moradores e turistas dos distúrbios e danos aos ecossistemas marinhos, no Município de Paraty, RJ.

\begin{tabular}{|c|c|c|c|c|c|c|c|c|c|c|}
\hline $\begin{array}{l}\text { Signifi- } \\
\text { cância }\end{array}$ & Avaliador & $\begin{array}{l}\text { Ruído de } \\
\text { barcos } \\
\text { recreativos } \\
\quad(\%)\end{array}$ & $\begin{array}{c}\text { Mer- } \\
\text { gulho } \\
(\%)\end{array}$ & $\begin{array}{c}\text { Pesca } \\
\text { esportiva } \\
(\%)\end{array}$ & $\begin{array}{c}\text { Pesca } \\
\text { por } \\
\text { esporte } \\
(\%)\end{array}$ & $\begin{array}{c}\text { Resíduos } \\
\text { sólidos } \\
\text { em } \\
\text { praias } \\
(\%)\end{array}$ & $\begin{array}{c}\text { Efluente } \\
\text { doméstico } \\
(\%)\end{array}$ & $\begin{array}{c}\text { Produtos } \\
\text { químicos } \\
\text { de } \\
\text { barcos } \\
(\%)\end{array}$ & $\begin{array}{c}\text { Erosão } \\
\mathrm{e} \\
\text { deposição } \\
(\%)\end{array}$ & $\begin{array}{c}\text { Arte- } \\
\text { sanato } \\
(\%)\end{array}$ \\
\hline \multirow[t]{2}{*}{$\mathrm{I}$} & Moradores & 41,7 & 50,0 & 66,7 & 75,0 & 8,3 & 0,0 & 8,3 & 16,7 & 41,7 \\
\hline & Turistas & 23,8 & 66,7 & 33,3 & 23,8 & 4,8 & 14,3 & 14,3 & 0,0 & 57,1 \\
\hline \multirow[t]{2}{*}{ II } & Moradores & 16,7 & 0,0 & 8,3 & 8,3 & 0,0 & 25,0 & 0,0 & 8,3 & 25,0 \\
\hline & Turistas & 19,0 & 23,8 & 23,8 & 14,3 & 0,0 & 4,8 & 0,0 & 14,3 & 19,0 \\
\hline \multirow[t]{2}{*}{ III } & Moradores & 16,7 & 0,0 & 16,7 & 0,0 & 25,0 & 8,3 & 16,7 & 0,0 & 8,3 \\
\hline & Turistas & 47,6 & 0,0 & 19,0 & 38,1 & 4,8 & 4,8 & 9,5 & 33,3 & 19,0 \\
\hline \multirow[t]{2}{*}{ IV } & Moradores & 0,0 & 8,3 & 0,0 & 8,3 & 8,3 & 0,0 & 8,3 & 0,0 & 0,0 \\
\hline & Turistas & 4,8 & 0,0 & 19,0 & 9,5 & 9,5 & 14,3 & 9,5 & 19,0 & 4,8 \\
\hline \multirow[t]{2}{*}{$\mathrm{V}$} & Moradores & 25,0 & 41,7 & 8,3 & 8,3 & 58,3 & 66,7 & 66,7 & 75,0 & 25,0 \\
\hline & Turistas & 4,8 & 9,5 & 4,8 & 14,3 & 81,0 & 61,9 & 66,7 & 33,3 & 0,0 \\
\hline
\end{tabular}

Como ressaltado por Miller Jr (2008), os ecossistemas marinhos, principalmente recifes de corais e algas, são extremamente vulneráveis a qualquer pressão antrópica. A poluição das águas decorrente das atividades turísticas em zonas costeiras representa uma série ameaça a estes ecossistemas.

Foram questionadas as opiniões sobre o aumento de volume gerado de resíduos sólidos e de efluentes domésticos devido à presença de turistas, especialmente em épocas de alta temporada. Constatou-se que a maioria de moradores $(58,3 \%)$ e de turistas $(47,6 \%)$ acredita que haja duplicação do volume de resíduos sólidos e efluentes domésticos durante altas temporadas. Uma porcentagem significativa acredita que a geração aumente uma vez e meia e poucos acreditam que haja aumento de apenas $1 / 2,1 / 3$ ou não haja aumento nenhum (figura 1 ). 
As destinações turísticas possuem limites quanto ao número de pessoas que nela podem circular. Assim, o excesso de visitantes em uma área provocará danos ao meio ambiente (FERRETTI, 2002; YOUELL, 2002). Elevado número de turistas em épocas de alta temporada pode agravar problema de gestão de resíduos sólidos e efluentes domésticos na destinação turística. No caso do efluente doméstico, mesmo havendo estações de tratamento, há o risco de suas vazões máximas serem excedidas, o que comprometerá a eficiência do processo de tratamento.

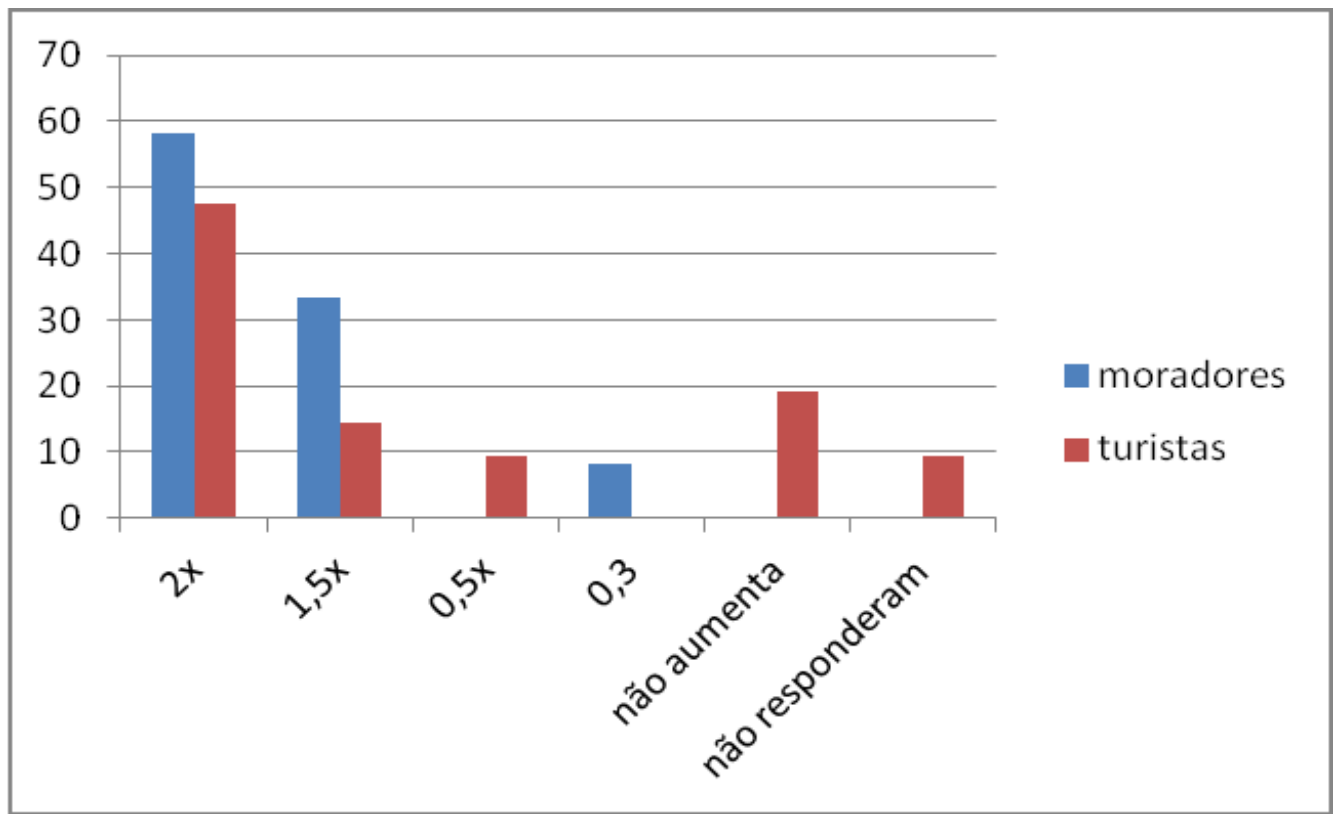

Figura 1 - Opiniões dos entrevistados, em porcentagem, sobre o aumento de volume gerado de resíduos sólidos e de efluentes domésticos devido à presença de turistas, no Município de Paraty, RJ

Casasola (2003) chama atenção para a gravidade dos problemas de saneamento em cidades turísticas litorâneas. Segundo o autor, ainda que existam redes de captação de águas residuais, uma parte dessas águas é despejada diretamente no mar ou em outros corpos de água, devido à deficiência e insuficiência das instalações, falta de conexão de alguns hotéis e residências ao sistema central de

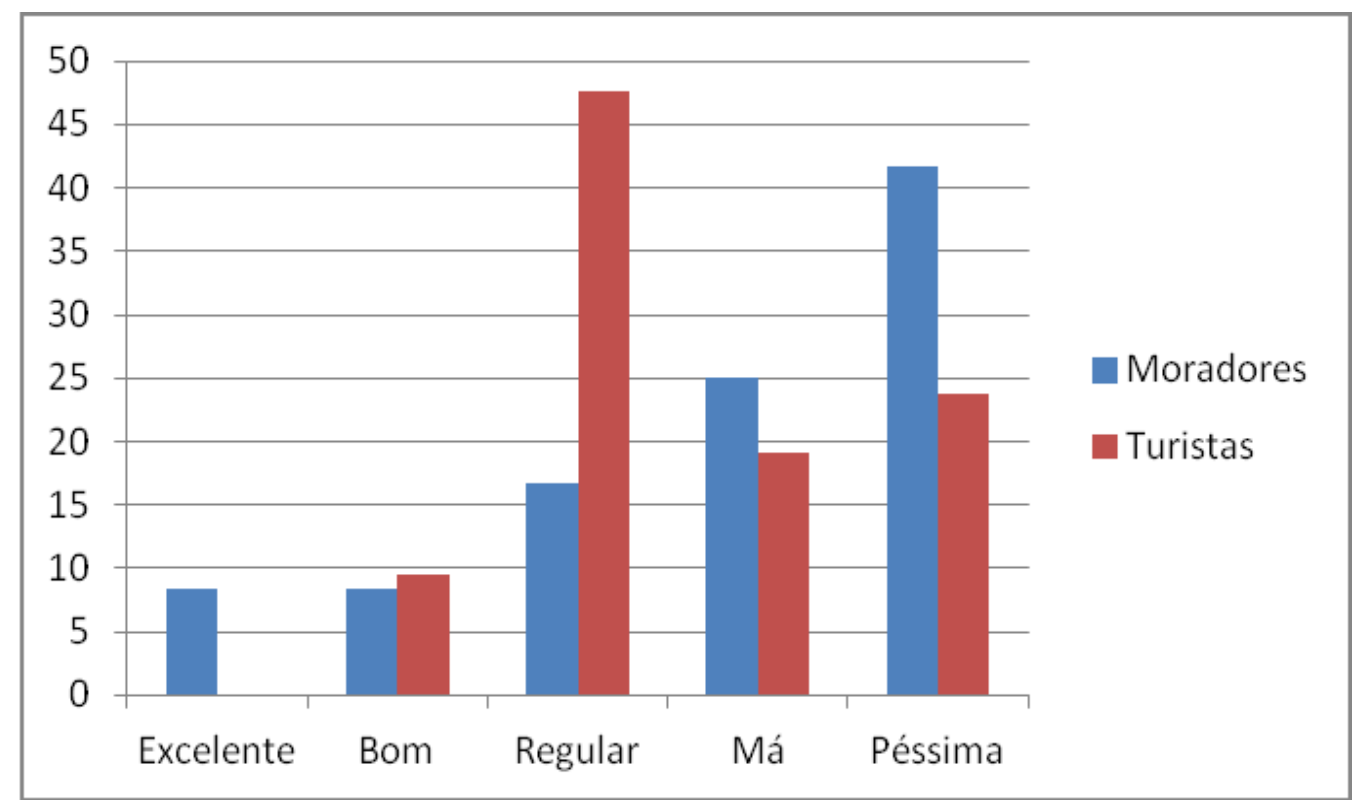

Figura 2 - Opiniões dos entrevistados, em porcentagem, sobre a atuação da Prefeitura quanto ao investimento em saneamento básico, no Município de Paraty, RJ 
drenagem, e falta de projetos de tratamento de efluente. Assim, os grandes volumes de desperdício gerados por elevados contingentes de turistas durante a alta temporada contribuem para a contaminação ambiental nas praias, no mar e em outros corpos de água.

O inchaço das destinações turísticas em épocas de altas temporadas e fins de semana prolongados poderá levar à dificuldade de solucionar os problemas de saneamento básico, porque a demanda sobre esses serviços é multiplicada, às vezes, por cem (FERRETTI, 2002).

A pesquisa procurou saber a opinião dos moradores sobre a atuação da prefeitura no que diz respeito ao saneamento básico. Essa atuação foi considerada péssima por $41,7 \%$ de moradores e 23,8 $\%$ de turistas; má, por $25,0 \%$ de moradores e $19,0 \%$ de turistas; regular, por $16,7 \%$ de moradores e $47,6 \%$ de turistas; bom, por $8,3 \%$ de moradores e $9,5 \%$ de turistas; excelente, por $8,3 \%$ de moradores e $0,0 \%$ de turistas (figura 2 ).

Ao governo municipal cabem as providências na demanda dos métodos paleativos que se referem à minimização dos problemas da superpopulação nos períodos de maior demanda do turismo.

Procuramos saber da percepção dos inquiridos da poluição sonora. Para a maioria $(33,3 \%$ de moradores e $38,1 \%$ de turistas), a poluição sonora no local é "ocasional e baixa", enquanto uma minoria ( $16,7 \%$ de moradores e $9,5 \%$ de turistas) considera que não há aumento da poluição sonora devido à presença de turistas; ressalve-se que nenhum morador considerou de "ocasional e elevada" a poluição sonora. A apuração completa dos resultados está representada na figura 3 .

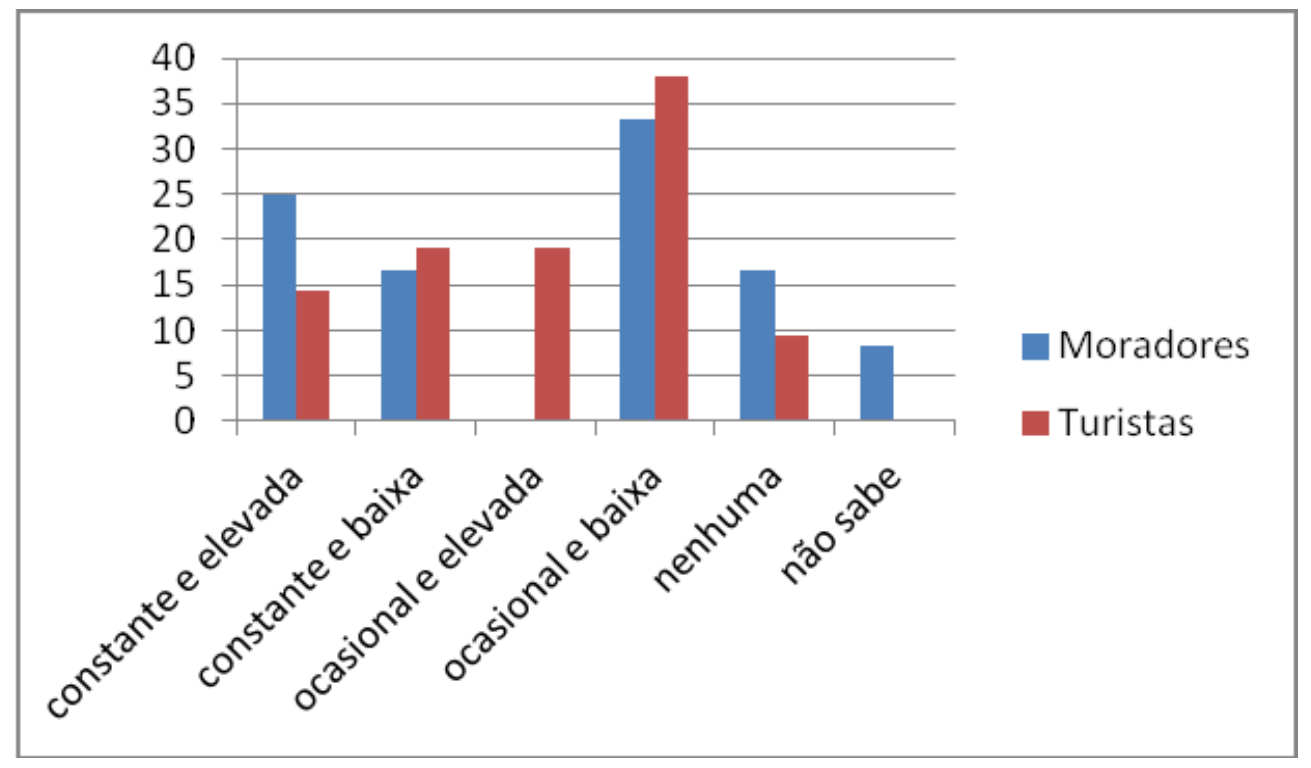

Figura 3 - Opiniões dos entrevistados, em porcentagem, sobre percepção da poluição sonora decorrente da presença de turistas, no Município de Paraty, RJ

Segundo Santos (1999), a poluição sonora é o principal agente da hipoacusia e da surdez em pessoas adultas, além de comprometer outros órgãos, aparelhos e funções do organismo. Ele afirma que a taxa e a extensão da perda auditiva depende do tempo e da intensidade de exposição à poluição sonora.

Moradores e turistas também foram inquiridos sobre a poluição visual. Os moradores tiveram opiniões conflitantes, pois, para 41,7\%, não ocorre poluição visual, enquanto, para $33 \%$, a poluição visual é "constante e elevada" e, para $25 \%$, é "ocasional e baixa". Já os turistas tiveram opiniões mais dispersas, com a maioria de $33,3 \%$ indicando que não ocorre aumento da poluição visual e uma minoria de $9,5 \%$ apontando que é baixa e constante (figura 4).

Note-se que a paisagem constitui um dos principais atrativos turísticos. Muitas pessoas se fazem deslocar a locais não habituais para apreciar paisagens com atributos naturais e antrópicos diferentes. Porém, a degradação visual de uma destinação turística poderá acarretar o declínio do fluxo dos mesmos.

Os inquiridos foram solicitados a opinarem sobre algumas afirmações, as quais relacionam a atividade turística a certas práticas que causam danos ao meio ambiente, tendo a opção de assinalar somente aquela(s) que consideravam verdadeira/verdadeiras. Para 33,3 \% de moradores e $50 \%$ 


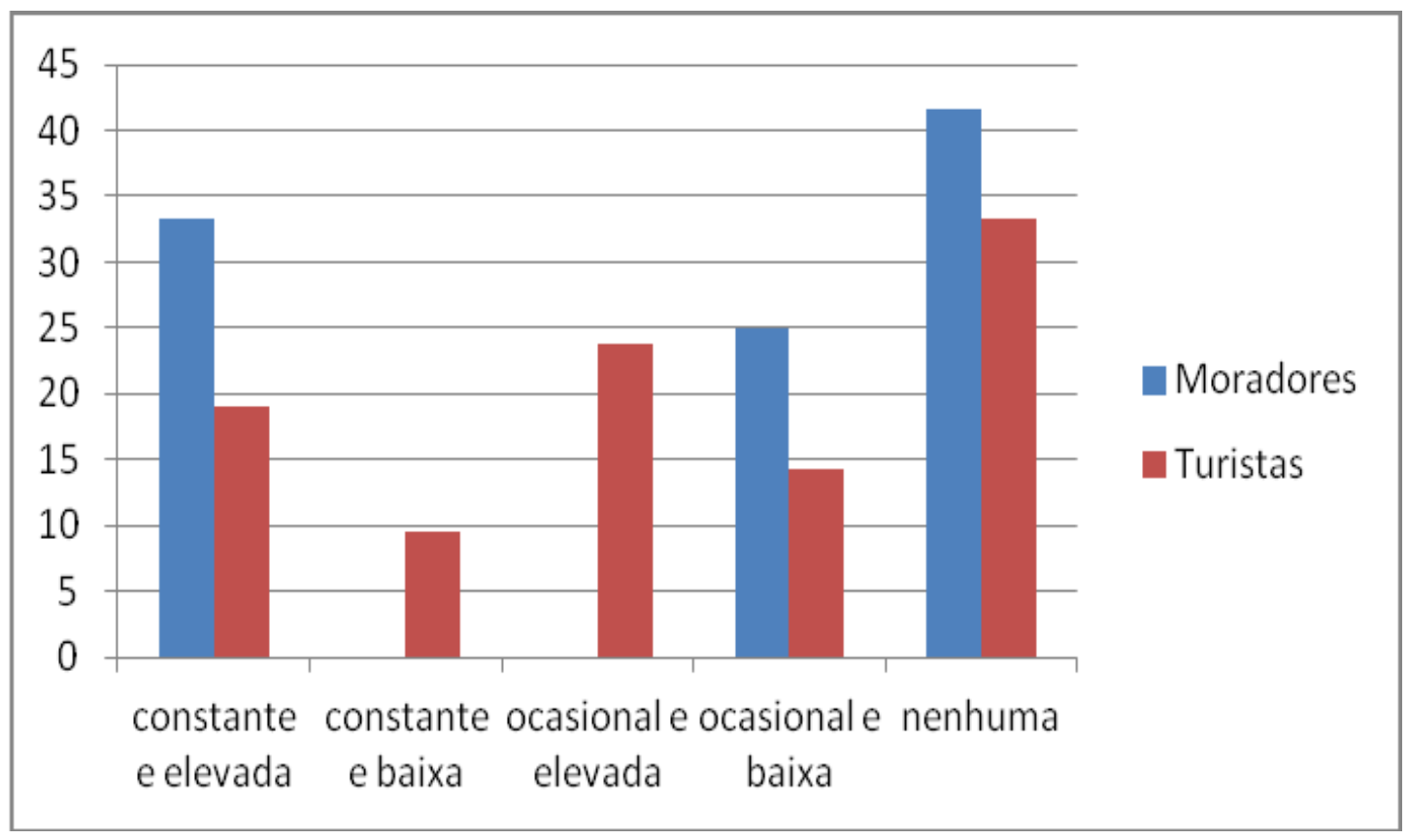

Figura 4 - Opiniões dos entrevistados, em porcentagem, sobre percepção da poluição visual decorrente da presença de turistas, no Município de Paraty, RJ

de turistas, a "construção de infraestruturas turísticas aumentou o desmatamento"; para 40,7 \% de moradores e $20 \%$ de turistas, o "turismo é um dos principais fatores responsáveis pelo aumento de construções irregulares"; para $11,1 \%$ de moradores e $23,3 \%$ de turistas, os "moradores capturam animais para venderem aos turistas"; para 11,1\% de moradores e 3,3 de turistas, os "turistas caçam, caça premeditada ou não"; e 3,7 \% de moradores e 3,3 \% de turistas não souberam ou não quiseram responder. O resultado comparativo entre turistas e moradores é expresso na figura 5.

De acordo com Casasola (2003), o turismo tem efeito urbanizador, transforma aldeias em

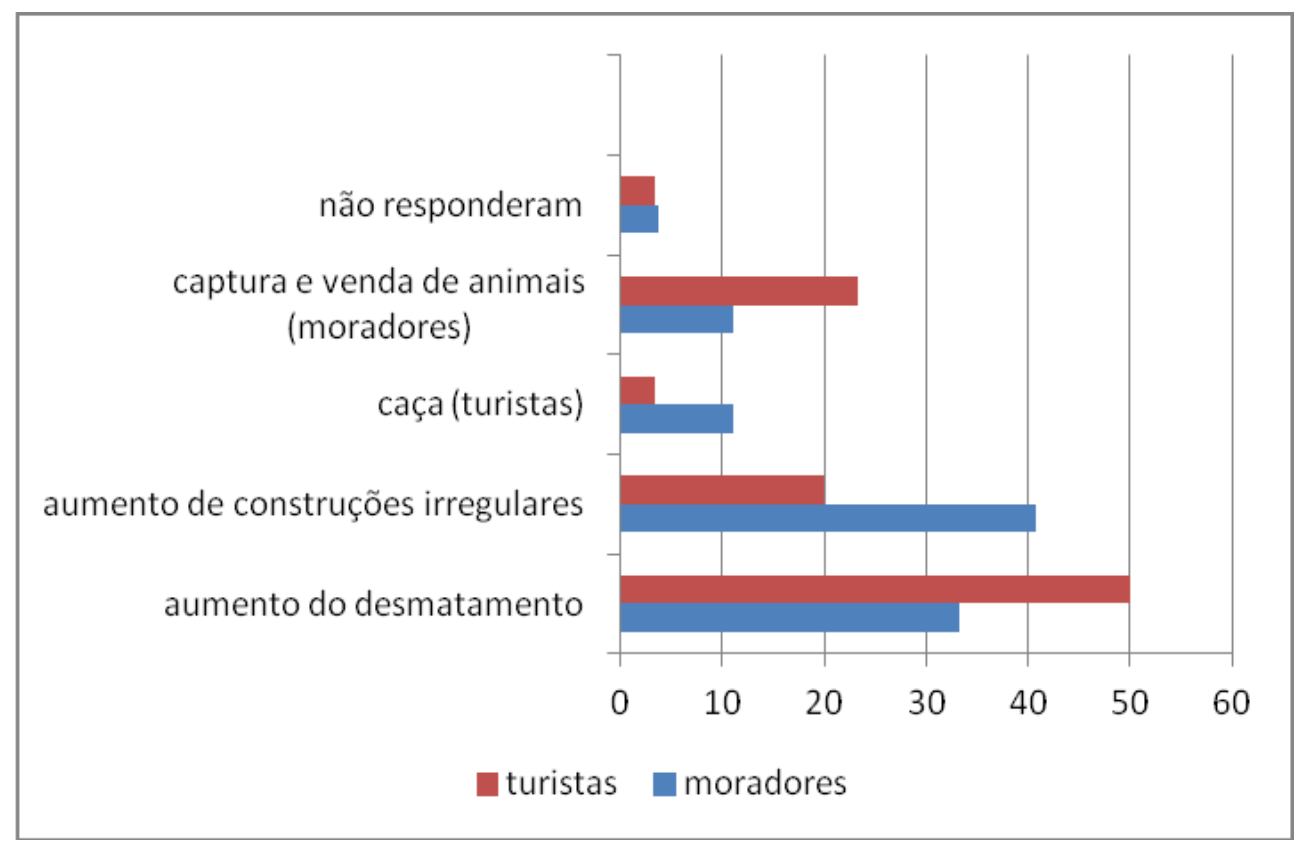

Figura 5 - Opiniões dos entrevistados, em porcentagem, quanto à avaliação de algumas atividades turísticas que podem provocar danos ambientais, no Município de Paraty, RJ 
cidades, produz crescimento desordenado com efeitos negativos.

Igualmente, foram solicitados a analisar três afirmações sobre impactos ambientais negativos, associados à destruição de manguezal, para construção de marinas de barcos usados por turistas, onde foram instruídos a assinalar apenas as afirmações com as quais concordavam (figura 6). Indicaram que essa destruição "provoca alterações negativas nos habitats dos organismos marinhos", "afeta a reprodução de peixes, crustáceos, moluscos e aves" e "origina erosão e assoreamento", respectivamente, nas proporções de $37,5 \%, 33,3 \%$ e $20,8 \%$ (moradores) e de $38,5 \%, 41 \%$ e $17,9 \%$ (turistas). 8,3\% de moradores e $2,6 \%$ de turistas não souberam ou não quiseram responder.

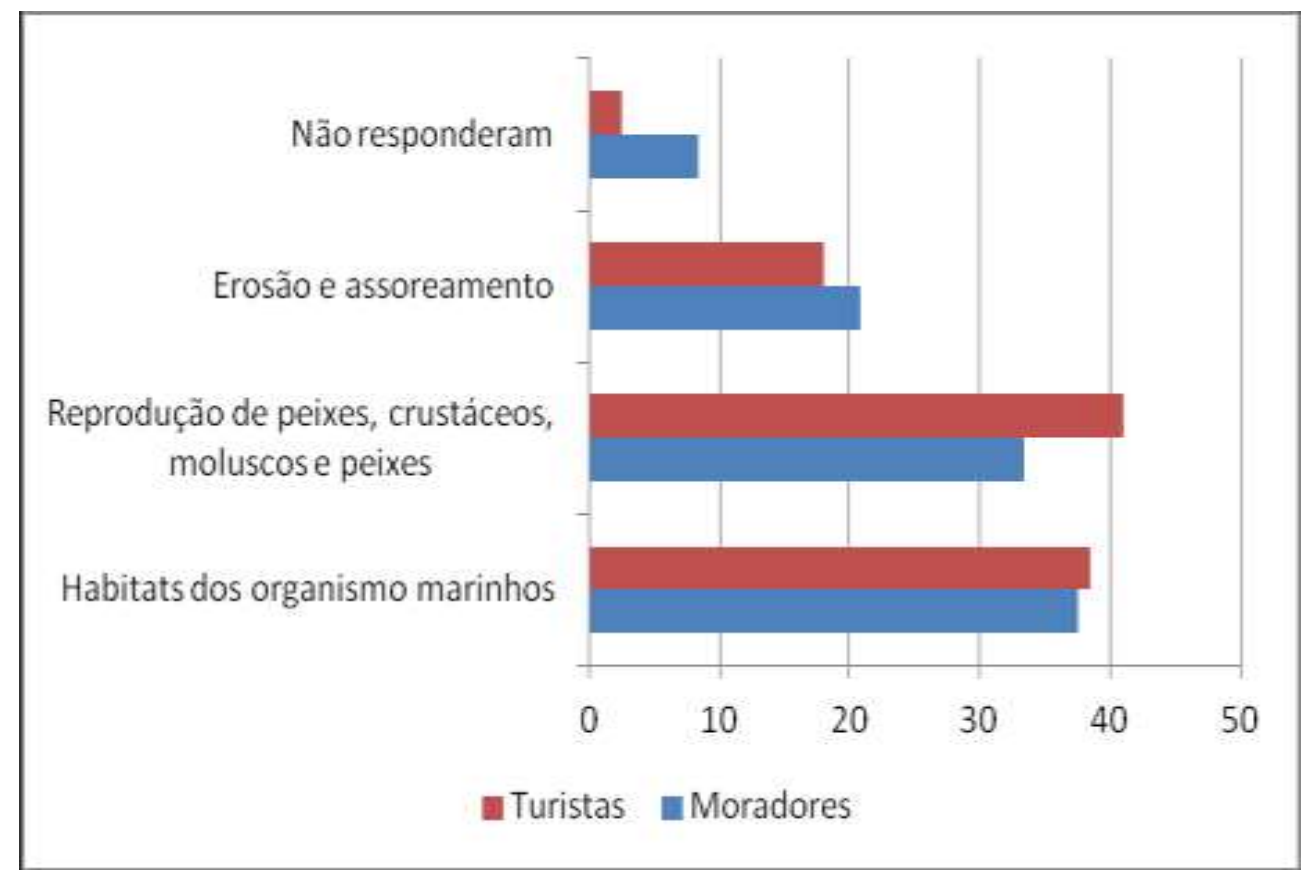

Figura 6 - Opiniões dos entrevistados, em porcentagem, sobre a avaliação de impactos ambientais associados à destruição de manguezais, no Município de Paraty, RJ

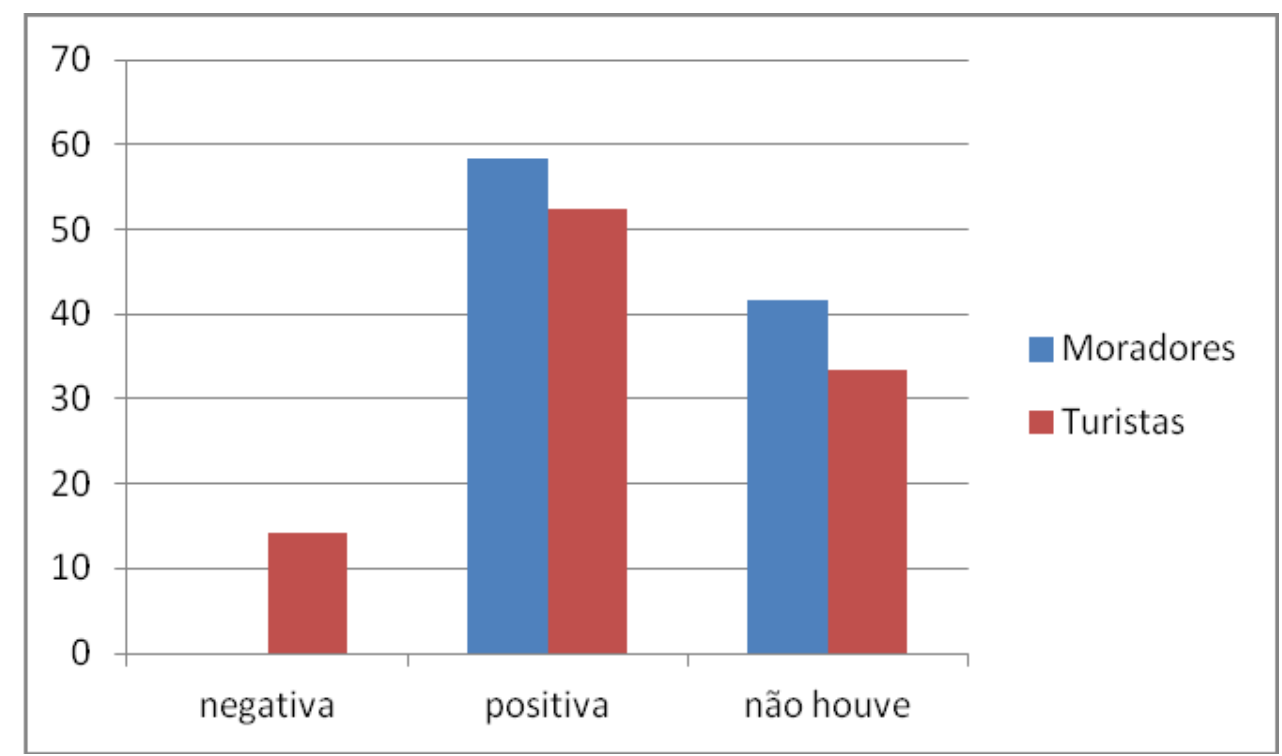

Figura 7 - Opiniões dos entrevistados, em porcentagem, sobre a influência do turismo à cultura local, no Município de Paraty, RJ 
O manguezal é de grande importância para muitas espécies animais e vegetais marinhas. Enquanto que para inúmeras espécies animais o manguezal é um "berçário" e abrigo, para recifes de corais, algas e outras espécies vegetais constitui uma barreira física que contém o processo erosivo, evitando o seu soterramento por sedimentos. Portanto, a destruição do manguezal aumenta a vulnerabilidade dos ecossistemas marinhos costeiros.

A influência do turismo no ambiente sociocultural também foi inquirida. Mais de metade de moradores $(58,3 \%)$ e de turistas $(52,4 \%)$ acreditavam que a destinação turística sofre influência positiva. Nenhum morador apontou como negativa a influência do turismo na cultura, enquanto $14,3 \%$ de turistas apontaram este aspecto. $41,7 \%$ de moradores e 33,3\% de turistas indicaram que não houve influência na cultura (Figura 7).

Em "Turismo e Ambiente", Casasola (2003) mostra o quão importante é levar em conta o aspecto sociocultural no planejamento do turismo. De acordo com o autor, um projeto turístico pode ser técnica e financeiramente aceitável e, ainda assim, ser prejudicial para a população nela envolvida. Isso se dá "quando [o projeto] atenta contra sistemas estabelecidos de crenças, valores, formas de vida e costumes".

Aos entrevistados, colocou-se, também, a questão de avaliação de nível de conscientização de moradores, de turistas, de poder público e de pescadores, no que diz respeito à preservação do ambiente. Em escala de cinco graus, Nível I (não existe conscientização) a Nível V (conscientização plena), o resultado obtido é apresentado no quadro 2.

Quadro 2 - Nível de conscientização de moradores e turistas quanto à preocupação com a preservação do ambiente dos moradores, turistas, poder público e pescadores, no Município de Paraty, RJ

\begin{tabular}{|c|c|cccc|}
\hline Nível & Avaliador & $\begin{array}{c}\text { Moradores } \\
\text { (\%) }\end{array}$ & $\begin{array}{c}\text { Turistas } \\
\mathbf{( \% )}\end{array}$ & Poder Público (\%) & $\begin{array}{c}\text { Pescadores } \\
\text { (\%) }\end{array}$ \\
\hline I & Moradores & 16,7 & 16,7 & 33,3 & 8,3 \\
& Turistas & 14,3 & 19,0 & 14,3 & 19,0 \\
II & Moradores & 0,0 & 8,3 & 0,0 & 0,0 \\
& Turistas & 19,0 & 33,3 & 28,6 & 23,8 \\
III & Moradores & 16,7 & 25,0 & 25,0 & 25,0 \\
& Turistas & 47,6 & 33,3 & 23,8 & 14,3 \\
IV & Moradores & 50,0 & 41,7 & 33,3 & 33,3 \\
& Turistas & 19,0 & 4,8 & 14,3 & 33,3 \\
V & Moradores & 16,7 & 8,3 & 8,3 & 33,3 \\
& Turistas & 0,0 & 9,5 & 19,0 & 9,5 \\
\hline
\end{tabular}

É indispensável a conscientização de todos os envolvidos na atividade turística quanto à conservação ambiental, pois o desenvolvimento e a manutenção dessa atividade depende de um meio ambiente sadio. A falta ou fraca conscientização dos envolvidos resultará no desequilíbrio negativo do ambiente, o que, salienta Valls (2006), implicará no início do declínio da destinação turística.

\section{CONCLUSÕES}

Com os dados acima apurados, conclui-se que tanto moradores quanto turistas perceberam danos ao meio ambiente provocados pela atividade turística no Município de Paraty-RJ. Os moradores tiveram maior percepção dos impactos ambientais negativos, o que pode refletir a sua posição de principal "vítima" de danos ambientais do turismo na localidade receptora. Portanto, a indústria turística não é uma "indústria limpa", agride ao meio ambiente como quaisquer atividades econômicas.

Ficou evidente a necessidade de melhorias no planejamento turístico, adoção de medidas, políticas e ações coordenadas, entre os setores público e privado, que priorizem a aspecto ambiental, visando à conservação do meio ambiente e o turismo sustentável, que constituem condições indispensáveis e básicas para o sucesso da indústria turística a longo prazo. A redução dos impactos ambientais negativos do turismo, como sugerido por Youell (2002), pode ser conseguida através de abordagens práticas, como envolvimento da comunidade no processo de tomada de decisões, controle da capacidade de carga, gerenciamento dos visitantes e do tráfego e instruções por meio de informações e marketing. 


\section{REFERÊNCIAS}

BARTHOLO JUNIOR, R; DELMARO, M; BADIN, L (Orgs). Turismo e sustentabilidade no Estado do Rio de Janeiro. Rio de Janeiro: Garamond, 2005.

BELTRÃO, O. di. Turismo: a indústria do século XXI. Osasco: Novo Século, 2001.

CASASOLA, L. Turismo e ambiente. Tradução de Waldelina Rezende. São Paulo: Roca, 2003.

DIAS, R. Introdução ao turismo. São Paulo: Atlas, 2005.

FERRETTI, E. R. Turismo e meio ambiente: uma abordagem integrada. São Paulo: Roca, 2002.

MILLER JR, G. T. Ciência Ambiental. São Paulo: Cengage Learning, 2008.

PARATY (Município). Secretaria de Turismo e Cultura. Plano diretor de desenvolvimento turístico do Município de Paraty, 2003. Disponível em: <www.cepa.tur.br/comtursap/PDT\%20Paraty.pdf>. Acesso em: 18 jun. 2013.

RUSCHMANN, D. V. de M. Turismo e planejamento sustentável: a proteção do meio ambiente. Campinas: Papirus Editora. 14 edição, 2008. 195 p. (Coleção turismo). Disponível em: <http://www.google.com.

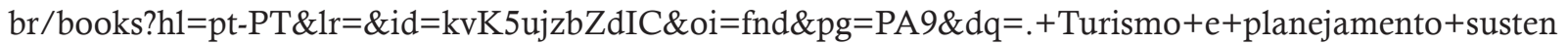
t $\%$ C3\%A1vel:+a+prote\%C3\%A7\%C3\%A3o+do+meio+ambiente\&ots=58-4swQhBm\&sig=1BP425U3ga LdYMG9S9qcjonlpA\&redir_esc $=\mathrm{y} \# \mathrm{v}=$ onepage $\& \mathrm{q}=. \% 20$ Turismo $\% 20 \mathrm{e} \% 20$ planejamento $\% 20$ sustent $\%$ C3\%A1vel $\% 3 \mathrm{~A} \% 20 \mathrm{a} \% 20$ prote $\% \mathrm{C} 3 \% \mathrm{~A} 7 \% \mathrm{C} 3 \% \mathrm{~A} 3 \mathrm{o} \% 20 \mathrm{do} \% 20$ meio $\% 20$ ambiente $\& \mathrm{f}=$ false $>$. Acesso em: 08 jul. 2013.

SANTOS, U. de P (Org.). Ruído: riscos e prevenção. 2. ed. São Paulo: Hucitec, 1999.

VALLS, J. Gestão integral de destinos turísticos sustentáveis. Tradução de Cristiano Vasques e Liana Wang. Rio de Janeiro: Editora FGV, 2006.

YOUELL, R. Turismo: uma introdução. Tradução de Beth Honorato. São Paulo: Contexto, 2002. (Turismo Contexto). 